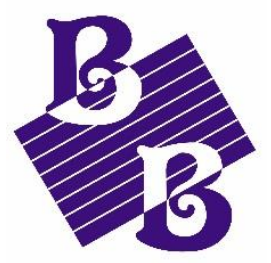

BioBacta

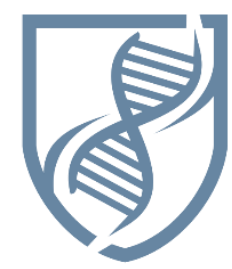

Journal of Bioscience and Applied Research

www.jbaar.org

\title{
Use of Date Palm Leaves with Some Animal feces For Microbial Activity for Biofertilizer production
}

\author{
Abd-El-Rahman Metwaly ${ }^{1,2}$, *Hesham Sayed Ghazzawy ${ }^{2,3}$ https://orcid.org/0000-0002-6616-1793, \\ Mohammed Ahmad Bkary ${ }^{1}$, Iheb Chakroun ${ }^{1}$, Muneeruddin Syed ${ }^{1}$ \\ ${ }^{1}$ Administration of Prevention \& Environmental Health. Al Madinah - Saudi Arabia \\ ${ }^{2}$ Central Laboratory of Date Palm Researches and Development, Agricultural Research Center, \\ Ministry of Agriculture, Giza, Egypt, \\ ${ }^{3}$ Date Palm Research Center of Excellence, King Faisal University, Saudi Arabia \\ *Corresponding Author: Hishamdates@hotmail.com
}

DOI: 10.21608/jbaar.2018.155799

\begin{abstract}
Production of compost using non-invested palm residues leads to organic products that improve the productivity of arable land. The purpose of this paper is to study the effect of concentrations of different animal feces with plant palm leaves on microbial activity. Samples of palm leaves and animal feces of camels, sheep, and chickens were collected and blended. Water and bakery yeast was added to improve the microbial activity of compost then the mixture is incubated according to the windrow method. Results are satisfactory and allowed us to obtain natural compost free of micro-organisms with chicken feces (50\%) without bakery yeast addition. Besides, sheep feces mixture, with added bakery yeast, gives microbial number decreases with percentage rise of feces.
\end{abstract}

\section{Keywords}

Camel feces, sheep feces, chicken feces, Palm date leaves, microorganism activities, anaerobic incubation.

\section{Introduction}

The Middle East has a large number of palm trees and the amount of tree trimming waste is very large. Very few of these wastes are recycled in the production of cages, baskets, and beach furniture, and the bulk is not invested (El-Habbab, et al., 2017). Saudi Arabia has about 23 million palm trees and it is the second-largest producer of dates. The biomass from the trimmed branches of palm trees amounts to more than 200,000 tons/year. This biomass waste can be used to produce many commercial products. There are several relevant technologies for the conversion of biomass and solid wastes into higher-value products. Palm tree leaves have complex nutrients such as cellulose, compounds that need to be digested by microbes to be used and converted to simple compounds that can be used optimally. For example, organic fertilizer (Alfadda, A and Abou Anya, A, 2016). 
Another example, pyrolysis of palm date waste is used to produce activated carbon and the waste can also be readily converted to liquid phenolic products. Liquid products are particularly interesting because they have a higher energy density and can be used to produce adhesives as well as biofuels for use in the power generation and transport sector. Experimental results have indicated potential opportunities of using the date biomass waste as a potential fuel in the Kingdom of Saudi Arabia (Hussain, A, 2014 and El-Habbab, et al., 2016). Cellulose is a sugar, polymer of glucose, of formula $\left(\mathrm{C}_{6} \mathrm{H}_{10} \mathrm{O}_{5}\right)_{\mathrm{n}}$ ( $\mathrm{n}$ between 200 and 3000). It is the main constituent of plants and in particular of the wall of their cells. It is not digested by humans but is nevertheless useful for the proper functioning of the intestines in the form of plant fibers. Herbivorous animals generally use enzymes of exogenous origin, that is to say, produced by the cells of the intestinal flora to digest the cellulose. The digestion of cellulose, in many herbivorous species, can only take place if the species establishes mutual or symbiotic relations, most often with bacteria, sometimes with fungi or protozoa capable of starting cellulose biodegradation in the rumen of ruminants (Akira Yamazawa et al, 2014). Yeast is one of the most important organisms that reproduce at high rates and contribute to accelerating the hydrolysis and digestion of compounds for cellulosic compounds by producing amino acids that help reproduce other cellulose hydrolyzers. Ruminants can benefit from complex compounds because their stomachs contain microorganisms capable of hydrolyzing these compounds into simpler compounds that benefit the animal during digestion. Some of these microbial species emerge in the extraction process. The plant has its food needs by adding compost to the soil witch is farming Organic (Allison H.L 2010). So production of compost using noninvested palm residues leads to organic products that improve the productivity of arable land and thus contribute to the quality and abundance of crops. The purpose of this paper is to study the effect of concentrations of different animal dung with plant palm residues on microbial activity.

\section{Material and methods}

The preparation method of the compost consists of: sorting, Slicing, adding stimulants (such as baker's yeast), adding a source of microbes (Animal Faces), control of humidity (addition of water or drying) then doing anaerobic fermentation during a long time (at list one month). Microbiological count and PH are done to supervise the process. This method is called the windrow method. Samples of palm leaves were collected and cut. Feces samples of camels, sheep, and chickens were also collected. Leaves and feces Blends (100g) ranging from $0 \%$ to $100 \%$ were made. The addition of water to the treatment to a content of $40 \%$ water in the mixture is also done. A quantity of $1 \%$ by weight of dried biological yeast was added to some treatments according to Table 01 and Table 02 . 
Table 01: Composition of Control Treatments (Mixture Leaves and Animal feces without yeast)

\begin{tabular}{|c|c|c|c|c|}
\hline \multirow{2}{*}{$\begin{array}{c}\text { Treatments } \\
\text { Code }\end{array}$} & \multirow{2}{*}{ Palm leaves \% } & \multicolumn{3}{|c|}{ Animal feces } \\
\hline & & Camel \% & Sheep \% & Chicken \% \\
\hline 1 & 100 & 0 & 0 & 0 \\
\hline 2 & 75 & 0 & 25 & 0 \\
\hline 3 & 50 & 0 & 50 & 0 \\
\hline 4 & 25 & 0 & 75 & 0 \\
\hline 5 & 0 & 0 & 100 & 0 \\
\hline 6 & 75 & 25 & 0 & 0 \\
\hline 7 & 50 & 50 & 0 & 0 \\
\hline 8 & 25 & 75 & 0 & 0 \\
\hline 9 & 0 & 100 & 0 & 0 \\
\hline 10 & 75 & 0 & 0 & 25 \\
\hline 11 & 50 & 0 & 0 & 50 \\
\hline 12 & 25 & 0 & 0 & 75 \\
\hline 13 & 0 & 0 & 0 & 100 \\
\hline
\end{tabular}


Table 02: Composition Treatments (Mixture Leaves and Animal feces plus 1g yeast added at each sample)

\begin{tabular}{|c|c|c|c|c|}
\hline \multirow{2}{*}{$\begin{array}{c}\text { Treatments } \\
\text { Code }\end{array}$} & \multirow{2}{*}{ Palm leaves \% } & \multicolumn{3}{|c|}{ Feces } \\
\cline { 3 - 5 } & & Camel \% & Sheep \% & Chicken \% \\
\hline 14 & 100 & 0 & 0 & 0 \\
\hline 15 & 75 & 0 & 25 & 0 \\
\hline 16 & 50 & 0 & 50 & 0 \\
\hline 17 & 25 & 0 & 75 & 0 \\
\hline 18 & 0 & 0 & 100 & 0 \\
\hline 19 & 75 & 25 & 0 & 0 \\
\hline 20 & 50 & 50 & 0 & 0 \\
\hline 21 & 25 & 75 & 0 & 0 \\
\hline 22 & 0 & 100 & 0 & 25 \\
\hline 23 & 75 & 0 & 0 & 0 \\
\hline 24 & 50 & 0 & 0 & 0 \\
\hline 25 & 0 & 0 & 0 & 0 \\
\hline & & & 0 & 0 \\
\hline
\end{tabular}


Subsequently, each treatment sample was empty of air and placed in an incubator under anaerobic conditions for two months. Each month, a sample of $1 \mathrm{~g}$ of each treatment sample is taken, and microbiological (yeasts, molds, bacteria, and Actinomycetes) and $\mathrm{pH}$ tests are carried out. Microbial analysis was done by isolating yeast, fungi, bacteria, and Actinomycetes using the dilution method. Dilution depends on microorganisms $\left(10^{6}\right.$ for Bacteria and yeast, $10^{5}$ for Actinomycetes, and $10^{4}$ for Fungi). And finally, a statistical analysis of the results using SAS software to determine the minimum significant difference is done.

\section{Results and discussion}

\subsection{Results for Total Count Colonies for Microorganisms and $\mathrm{pH}$ after one month in anaerobic incubation of Control Treatments}

After one month of incubation under anaerobic conditions, data Analyses of Total Count Colonies for Microorganisms for different Control Treatments (Mixture Leaves and Animal feces without yeast) (Table 01) showed that there are significant differences in the results for the different treatments. The analysis of data on the number of microorganisms for different treatments after one month of incubation under anaerobic conditions (Table 03) showed that there are significant differences in the results for the treatments. The best treatment is for number 14, which corresponds to the $100 \%$ leaf and which gives the highest number of bacteria and molds with the lowest $\mathrm{pH}$ value. On the other hand, the number of bacteria and molds is lowest for treatment number 24 where the $\mathrm{pH}$ is high and this corresponds to treatment with $50 \%$ date leaves and $50 \%$ chicken faces. The highest number of bacteria was for treatment 23 the highest number of fungi was for treatment 1 and the highest number of yeasts was for treatment 1, 11, 18, and 21. The highest $\mathrm{pH}$ number is for treatments number 26 and was 8.38. Table 03: Total Count Colonies for Microorganisms and $\mathrm{pH}$ after one month in anaerobic incubation of Control Treatments (Leaves and Animal feces mixture without yeast) 
Table (03) Results for Total Count Colonies for Microorganisms and pH after one month in anaerobic incubation of Control Treatments

\begin{tabular}{|c|c|c|c|c|c|}
\hline $\begin{array}{l}\text { Treatments } \\
\text { code }\end{array}$ & Yeast $10^{6}$ & Fungi $10^{4}$ & Bacteria $10^{6}$ & Actino $10^{5}$ & $\mathrm{pH}$ \\
\hline 1 & 1 & 41 & 1 & 0 & 5.4 \\
\hline 2 & 0 & 0 & 8 & 0 & 5.7 \\
\hline 3 & 0 & 0 & 4.75 & 0 & 6.36 \\
\hline 4 & 0 & 0 & 4.75 & 0 & 6.4 \\
\hline 5 & 0 & 0 & 4.75 & 0 & 5.7 \\
\hline 6 & 0 & 7.33 & 6 & 0 & 6.2 \\
\hline 7 & 0 & 3 & 0 & 0 & 6.38 \\
\hline 8 & 0 & 12.33 & 11.66 & 0 & 7 \\
\hline 9 & 0 & 0.33 & 13.66 & 0 & 6.8 \\
\hline 10 & 0 & 0 & 10 & 0 & 7.7 \\
\hline 11 & 1 & 0 & 15.33 & 0 & 8.19 \\
\hline 12 & 0 & 0 & 3.66 & 0 & 8.19 \\
\hline 13 & 0 & 0 & 0.33 & 0 & 8.4 \\
\hline 14 & 0 & 23.66 & 30.66 & 0 & 5.17 \\
\hline 15 & 0.66 & 0 & 9 & 0 & 5.6 \\
\hline 16 & 0 & 0 & 7 & 0 & 6.00 \\
\hline 17 & 0 & 0 & 4 & 0 & 6.35 \\
\hline 18 & 1 & 0 & 6.33 & 0 & 8 \\
\hline 19 & 0 & 15 & 1 & 0 & 6.28 \\
\hline 20 & 0 & 0 & 5.66 & 0 & 6.64 \\
\hline 21 & 1 & 4.33 & 17 & 0 & 6.16 \\
\hline 22 & 0 & 0 & 19 & 0 & 6.3 \\
\hline 23 & 0 & 0 & 36 & 0 & 7.98 \\
\hline 24 & 0 & 0 & 0 & 0 & 8.16 \\
\hline 25 & 0.66 & 0 & 19 & 0 & 8.28 \\
\hline 26 & 0 & 0 & 2.33 & 0 & 8.38 \\
\hline
\end{tabular}




\subsection{Results for Total Count Colonies for} Microorganisms and $\mathrm{pH}$ after two months in anaerobic incubation of Control Treatments

Data Analyses of Total Count Colonies for Microorganisms for different Control Treatments (Mixture Leaves and Animal feces plus 1g yeast added at each sample) (Table 02) after two months of incubation under anaerobic conditions showed that there are significant differences in the results for the different treatments. The analysis of data on the number of microorganisms for different treatments after two months of incubation under anaerobic conditions showed that there are significant differences in the results for the treatments. The best treatment is for numbers 1 and 14 , which corresponds to the $100 \%$ leaf and which gives the highest number of bacteria and yeast with a low $\mathrm{pH}$ value (round 6.85). On the other hand, the lowest number of bacteria, molds, and yeast (zero for each) are for treatment number 11 where the $\mathrm{pH}$ is high (8.67) and this corresponds to treatment with $50 \%$ date leaves and $50 \%$ chicken feces without added bakery yeast treatment. The highest number of bacteria was for treatment 01 and 14 the highest number of fungi was for treatment 19 and the highest number of yeasts was for treatment 14 . The highest $\mathrm{pH}$ number is for treatments number 26 and it is 8.71. We found the presence of Actinomycetes for treatments 18 and 21. The presence of Actinomycetes was within treatments 18 and 21 and for $\mathrm{pH} 7.15$ and 7.08. When Actinomycetes is present, there is a very low number in Bacteria, fungi, and yeast (less than for the other treatments). 
Table (04): Total Count Colonies for Microorganisms and $\mathrm{pH}$ after two months in anaerobic incubation of Control Treatments (Leaves and Animal feces mixture with yeast)

\begin{tabular}{|c|c|c|c|c|c|}
\hline $\begin{array}{c}\text { Treatments } \\
\text { code }\end{array}$ & Yeast $10^{6}$ & Fungi $10^{4}$ & Bacteria $10^{6}$ & Actino $10^{5}$ & $\mathrm{pH}$ \\
\hline 1 & 76.66 & 0 & 180 & 0 & 6.92 \\
\hline 2 & 0 & 0 & 3.66 & 0 & 6.97 \\
\hline 3 & 0 & 0 & 23.66 & 0 & 7.27 \\
\hline 4 & 0 & 0 & 2.66 & 0 & 6.04 \\
\hline 5 & 0.33 & 0.33 & 3 & 0 & 6.2 \\
\hline 6 & 3.33 & 0.33 & 9.66 & 0 & 6.84 \\
\hline 7 & 3 & 0 & 3.33 & 0 & 7.22 \\
\hline 8 & 3.33 & 2.66 & 6 & 0 & 7.54 \\
\hline 9 & 0 & 0.33 & 8 & 0 & 7.29 \\
\hline 10 & 0 & 7 & 7.66 & 0 & 6.79 \\
\hline 11 & 0 & 0 & 0 & 0 & 8.67 \\
\hline 12 & 0 & 0.66 & 7 & 0 & 8.31 \\
\hline 13 & 0 & 0 & 25 & 0 & 8.5 \\
\hline 14 & 113.66 & 0 & 180 & 0 & 6.81 \\
\hline 15 & 0 & 0 & 89.66 & 0 & 5.86 \\
\hline 16 & 0 & 0 & 3 & 0 & 5.53 \\
\hline 17 & 2 & 0 & 0 & 0 & 5.25 \\
\hline 18 & 0 & 0.33 & 2 & 1 & 7.15 \\
\hline 19 & 17.33 & 10 & 22.33 & 0 & 6.77 \\
\hline 20 & 40.33 & 0.33 & 16.33 & 0 & 6.68 \\
\hline 21 & 0 & 0 & 15 & 1 & 6.8 \\
\hline 22 & 45 & 0 & 14 & 0 & 7.0 \\
\hline 23 & 0 & 0.33 & 3.33 & 0 & 7.91 \\
\hline 24 & 0 & 3.33 & 12.66 & 0 & 8.47 \\
\hline 25 & 0 & 0.33 & 25.66 & 0 & 8.44 \\
\hline 26 & 0 & 0 & 10.66 & 0 & 8.71 \\
\hline
\end{tabular}

Least Significant Difference 6.9282

Least Significant Difference 1.74 


\subsection{Discussion}

In the case of addition of bakery yeast to treatment $100 \%$ date leaves after one-month anaerobic incubation, bacterial development increases and fungi development decreases and $\mathrm{pH}$ is a stable weak acid. These results show that, after two months, the best microbiological activity and the lowest $\mathrm{pH}$ number (near neutrality) are in the case of $100 \%$ palm leaves with and without bakery yeast addition. The addition of bakery yeast affects only yeast activity but does not affect the $\mathrm{pH}$. On the other hand the same statement with bakery yeast addition, after two months, there is no influence on bacterial growth but increase yeast growth and the $\mathrm{pH}$ stay neutral with and without yeast addition.

In the case of sheep feces mixed with palm leaves with and without yeast addition, after one and two months, the bacterial number decreases with animal feces rate. At the same time fungi and yeast disappear and the $\mathrm{pH}$ is a weak acid.

In the case of camel feces mixed with palm leaves without yeast addition, the bacterial number increases with animal feces rate. In this case fungi number decreases, yeast disappears and the $\mathrm{pH}$ is a weak acid (near neutrality) with exception of fifty $\%$ feces and leaves where microbial activity decreases. On the other hand, after one month, the addition of bakery yeast increases bacterial and yeast number, the fungi number decreases, and the $\mathrm{pH}$ is weak basic (near neutrality) for all treatments. After two months, the addition of bakery yeast increases bacterial and yeast number, the fungi number decreases, and the $\mathrm{pH}$ is weak basic (near neutrality) for all treatments.

There is a high efficiency of the Camel in the digestion of low - nutrient-rich material of high fiber content has been observed in studies comparing the ability of camels, cattle, sheep, and goats to digest cellulite. Camels are more efficient in digesting fiber since the time of holding the material in the crumbs of camels is longer than other animals, which expose these materials for a longer period of fermentation, in addition to the acidity of the spray of camels is more suitable for microbe's digestion of fiber. The digestion in camel rumen depends on thousands of microbial species, which include bacteria, fungus. These microbes can produce enzymes that digest the fibers and other complex sugars and can not be produced from any animal at all, making them important not only in digestion inside the rumen but also in many industries such as biofuel production. Bacteria represent the vast majority of stomach microorganisms $(93 \%)$ and fungi $(1 \%)$. This study confirms that the camel stomach contains a high variety of microbes; in addition to that most of the infestation microbes can digest high fiber material (Alaa Rabii, 2018) which is confirmed by this study through Camel feces bacteria and fungi number.

In the case of chicken feces mixed palm leaves, after one month, without yeast addition, the bacterial number increases with animal feces rate till 50\% feces and leaves mixture then it decreases when $\mathrm{pH}$ increase. Fungi disappear and yeast number is very low with fifty $\%$ feces and leaves mixture. An increase in animal feces rate conduct to a pH increase (From 7.7 to 8.4). On the other hand, feces mixed palm leaves with $1 \mathrm{~g}$ yeast addition, with $50 \%$ under $\mathrm{pH} 8.16$ all microorganisms disappear. Bacteria decrease till $50 \%$ feces and leaves mixture then it rises at $75 \%$ and finely decreases at $100 \%$ with disappears of fungi and yeast where $\mathrm{pH}$ is at the highest value (8.38). The composition of chicken feces is shown in (BOUGHABA R., 2012) and explains why this media is favorable to bacterial growth $(\mathrm{N}, \mathrm{P} K$. number is very high). After two months, with $50 \%$ of $\%$ feces and leaves mixture, all microorganisms disappear. The number of bacteria rises with the disappearance of fungi and yeast and $\mathrm{pH}$ grows to 8.5. When the microbes grow in the rumen, they produce amino acids, which are the foundation stone for building the protein. The bacteria can use ammonia or urea, a source of inorganic nitrogen to build amino acids. Without the conversion process, the presence of ammonia and urea is useless, the bacterium manufactured in the rumen is digested in the small intestine and is a major source of amino acids for ruminants (Bowen, R.A., 2007). Whereas when bakery yeast addition, number of bacteria grows within feces rate till $75 \%$ and decrease at $100 \%$ feces. Fungi's maximum number is at $50 \%$ then it decreases to disappear at $100 \%$ feces. The $\mathrm{pH}$ is alkaline in all cases and it rises with feces rate 
to $100 \%$ where $\mathrm{pH}$ is 8.71 . The high microbial activity in compost-containing chicken feces can be explained by its higher percentage of NPK which is confirmed in (Nooreldeen S. A., 2007) publication. In general addition of bakery yeast to animal feces, palm leaves mixture leads to an increase in microorganism number (especially for bacteria and fungi) and this may be due to the availability of amino acids which is essential for microorganism growth. The disappearance of yeast is linked to $\mathrm{pH}$ rise. The $\mathrm{pH}$ decrease leads to the disappearance of some bacteria and fungi and the appearance of others. Alkaline media of Chicken feces influence negatively on yeast in the first step, then on fungi, and finally on bacteria.

\section{Conclusion}

Results obtained following the fermentation of the date leaves and animal waste mixtures are satisfactory. Indeed the difference between the three types of animal feces is clear. This study allowed us to obtain natural compost free of microorganisms with chicken faces. The best compost according to free of microorganism is produced from $50 \%$ chicken feces and $50 \%$ date palm leaves without yeast after two months. This result can improve the acid soils. Thus this will improve plant growth regarding $\mathrm{pH}$ levels. Besides, results obtained show the positive effect of yeast on compost production. Results show, too, that in the case of sheep feces mixtures with bakery yeast, the microbial number falls with a percentage rise of feces. On the other hand, it is possible to improve the composition of the compost by adding mineral additives such as NPK. And in all cases, it is necessary to make sure of the absence of heavy metals, dangerous for humans, animals, and the environment.

\section{Reference}

- Ahmad Hussain, Aamir Farooq, Mohammad Ismail Bassyouni, Hani Hussain Sait, Mahmoud Abo El-Wafa, Syed Waheedul Hasan, Farid Nasir Ani. Pyrolysis Of Saudi Arabian Date Palm Waste: A Viable Option For Converting
Waste Into Wealth. Life Sci J 2014;11(12):667-671].

- Akira Yamazawa 1,2, Tomohiro Iikura 2, Yusuke Morioka 2, Amiu Shino 3, Yoshiyuki Ogata 4, Yasuhiro Date 2,3 and Jun Kikuchi, Cellulose Digestion and Metabolism Induced Biocatalytic Transitions in Anaerobic Microbial Ecosystems, Metabolites 2014, 4, 36-52; doi:10.3390/metabo4010036

- Alaa Rabii, 2018: Microbial Crust Camels and Their Importance, International Conference on Genetic Engineering, 26 to 29 April, Sadat City University of Menoufia, Institute of Genetic Engineering Lethbridge Research Center, Canada

- Alfadda, A. Abou Anya, A, 2016: Byproducts of palms, their types and economic importance, PP225

- Allison H.L 2010, The. Chapter12, The suppression plant pathogens by of vermicompost, Vermiculture, book technology.

- Boughaba r., 2012, Etude de la gestion et valorisation des fientes par le Lombricompostage dans la willaya de Constantine, Magister, Université de Mentouri, , Algeria, PP98

- Bowen, R.A. (2007), Digestive anatomy in ruminants. Course, Agricultural Science I, Introduction to Animal Nutrition, Monogastric Digestive System, University of Missouri-Columbia, Page 1 of 7 ,

- Brahim Bushara, 2014, Digestive system in birds and digestion processes, University of Kordofan - Sudan.

- El-Habbab, M. S and Ghazzawy, H.S (2016): Wholesale and Retail Price Integration for Date Palm in Saudi Arabia. Indian Journal of Research, ISSN - 22501991, Volume 5, Number 9, pp. 174-178.

El-Habbab, M. S., M.S., Al-Mulhim F., AlEid, S., Abo El-Saad M., Aljassas, F., Sallam, A, and Ghazzawy, H.S (2017): Assessment of Post-Harvest Loss and Waste for Date Palm in the Kingdom of Saudi Arabia. International Journal of Environmental \& Agriculture Research (IJOEAR), ISSN - 2454-1850, Volume 3, Number 6, pp. 1-11. 
- Nooreldeen Shawqi Ali, 2007: fertilizer technology and uses, Ministry of Higher Education \& Scientific Research, College of Agriculture- University of Baghdad 